\title{
The Maker Culture and the Open Source Model in the Architecture, Urbanism and Design Context: The Fabrication and Sharing of a Game for Design Teaching
}

\section{SIGRADI2018 TECHNOPOLITICAS \\ xxii congresso da sociedade iberoamericana de gráfica digital 22th conference of the iberoamerican society of digital graphics 07|08|09|novembro|2018 iau usp | são carlos | sp br}

\author{
Frederico Braida \\ Universidade Federal de Juiz de Fora | Brazil | frederico.braida@ufjf.edu.br \\ Icaro Chagas \\ Universidade Federal de Juiz de Fora | Brazil | icaro.chagas@arquitetura.ufjf.br \\ Isabela Ruback Cascardo de Almeida \\ Universidade Federal de Juiz de Fora | Brazil | isabela.ruback@arquitetura.ufjf.br \\ Janaina Mendes de Castro \\ Universidade Federal de Juiz de Fora | Brazil | janaina.mendes@arquitetura.ufj.br
}

\begin{abstract}
This article aims to present a discussion about the maker culture and an experience of fabricating and sharing a set of building blocks designed as a didactic tool for teaching architectural design within the premises of do-it-yourself culture and an open source model. Methodologically, the article is the result of both a bibliographical research and an empirical research, from which, in contemporary times, is evidenced the strengthening of flexible, collaborative, creative and innovative processes, prevailing premises in the maker movement.
\end{abstract}

Keywords: Maker culture; Open source; Teaching; Democratization; Digital culture.

\section{INTRODUCTION}

We are faced with a contemporary movement towards the universalization of learning: the maker culture (Weiss, 2008; Mellis \& Buechley, 2011; Ames et al., 2014), which is based on the empowerment of individuals, above all from the stimulus to the creative making and access to the content available on digital media, on the internet.

The idea behind the maker culture is to create and develop new products (concrete or digital ones), using various software or tools (especially digital), in open spaces, workshops or laboratories (Anderson, 2012 in Schön, Ebner \& Kumar, 2014). This movement involves innovative, economically accessible forms of production, and do-it-yourself (DIY) work, being considered by many authors as the fourth Industrial Revolution (Schwab, 2016).

One of the nine principles of the maker movement, according to Hatch (2016), is the sharing, which consists of dividing a product and its production instructions with other makers, with the shared knowledge being the greatest reward among the supporters of the movement. This principle, along with the strong dissemination, along the years, of spaces for doing and learning makerspaces, fab labs (fabrication laboratory), hackerspaces and others - reveals the strong influence of the maker culture on the democratization of knowledge. Within this culture, open source orientation is valued and fostered, which allows the appropriation and modification of a technique, software or machinery for its distribution and improvement (Pacini, Passaro \& Henriques, 2017).
Thus, permeating the fields of human knowledge, the theme of the maker culture, articulated with the issues of the open source universe (Kera, 2017), has gained relevance in the era of digital culture. Also, in the fields of Architecture, Urbanism and Design, this theme has been in evidence, especially after the dissemination of digital manufacturing technologies and the extensive implantation of fab labs.

In this context, in the field of Education, whether formal or informal, we have witnessed the democratization of teaching-learning processes (Okada, 2017). Also in the teaching of architecture, urbanism and design, several initiatives that incorporate digital technologies and collaborative modes of production can be highlighted.

It is within this scenario that this paper is inserted. In this work, the results of a research in which an experiment of production and sharing of a set of blocks of assembly was conceived as a didactic tool for the teaching of architecture project within the assumptions of the culture of the make- yourself and an open source model. Thus, the main objective of this article is to present a case in which the premises of the maker movement and the open source platforms were fundamental for the development of a proposal that aims to contribute with a didactic material aimed at the formal phase of the Architecture and Urbanism design.

For this, the paper is structured in five sections. It begins with some considerations on the maker culture and its unfolding in the field of Architecture, Urbanism and Design 
in the contemporaneity. Next is presented the development of the building block game called Archbricks, which is about a result of a research financed by the State Research Support Foundation FAPEMIG, in the scope of the LEAUD, from the Faculty of Architecture and Urbanism of the Federal University of Juiz de Fora (FAUUFJF). At the end, it is discussed how the game had its conception, production and distribution conceived from the premises of the maker movement, contributing to the socialization of the open knowledge to the possibilities of collaboration, as well as some reflections ascending from the critical analysis of the different phases of the research.

\section{CONSIDERATIONS ABOUT THE MAKER CULTURE}

The maker culture can have its origin understood through some significant events throughout history. The emergence of fab labs, for example, came about from the great success of a lecture at the Massachusetts Institute of Technology (MIT) Center of Bits and Athoms (CBA) in 2001. The initial idea was to teach a small group of students to use the machinery of the CBA, however, such laboratory was equipped with digital manufacturing tools and students were enthusiastic about the possibility of producing objects for personal use. Inspired by the success of this first class in 2003, the CBA began an extension project supported by the National Science Foundation (Gershenfeld, 2012), which provided digital and manual tools in a college space so that users could actually produce things, which come to be known as fab lab.

The years that followed inaugurated the spread of fab labs throughout the world, and the leasing of new facilities in countries on all continents is impressive. In recent years, the total number of fab labs has expanded considerably, forming a network connected by the democratization of production and knowledge, in favor of the maker movement (see https://www.fablabs.io/organizations).

In 2005, a major magazine entitled MAKE (https://makezine.com/) was available in the United States, which is published every two weeks and focuses on projects involving computers, robotics, electronics and other areas (Schön, Ebner \& Kumar, 2014). The magazine organized the first Maker Faire in San Mateo in 2006, where exhibitors displayed artifacts produced by themselves, which occurs annually to this day. At the same time, in the same year, the first commercial makerspace was inaugurated, TechShop (whose company went bankrupt February 26, 2018, see http://www.techshop.ws), a studio equipped with digital manufacturing tools, such as such as 3D printers, laser cutters, vinyl plotters and computer aided design (CAD) software, which anyone can use for a small fee (Schön, Ebner \& Kumar, 2014).

The Maker Faires also spread and inaugurated its first event in Rome in 2013 (European Maker Faire) and, in 2014, in the White House, setting up an event of an exhibiting character and very important for the supporters of the maker movement to expose their solutions and products. Nowadays, we have versions of this faire around the world, including in Brazil. In 2018, the cities of Rio de Janeiro and Belo Horizonte will receive editions of Maker Faire Mini (see https://makerfaire.com/map/).
Although this movement is less than 20 years old, the review of these events leads us to understand the impact of the maker culture in contemporary societies; and it is no wonder that many consider it as a revolution. The expansion of sites that stimulate digital production and manufacturing, along with the sharing of all the knowledge acquired by "doing", amplifies the possibilities of scientific advancement, as well as being a new alternative to the detriment of industrial overproduction, also supporting sustainable development and, from a political point of view, nurturing access to information and knowledge.

\section{MAKER CULTURE IN THE FIELD OF ARCHITECTURE, URBANISM AND DESIGN}

If we understand Architecture, Urbanism and Design as a path between idea and materialization, it makes clear that the maker movement would find great possibilities of use in these fields of knowledge and human acting. There, perhaps, lies the main justification for the rapid expansion of fab labs, mainly those linked to higher education institutions, especially the schools of Architecture, Urbanism and Design.

Nowadays, the physical models have returned to a great importance, since the direct communication existing between digital files and physical models (file-to-factory process) can be easily established (Dunn, 2012). In this context, rapid prototyping, as well as digital fabrication, has been an important tool for testing and manufacturing products, since, by generating physical models quickly, reduces the gap existing between a project and its execution.

In our time, the Fab Foundation, linked to MIT, is associated with fab labs spread all over the world, many of them linked to the universities and colleges of Architecture, Urbanism and Design. In several laboratories, there are architects and designers as the main enthusiasts.

In a survey conducted in 2015 for the exhibition Homo Faber: Digital Fabrication in Latin America, 31 digital manufacturing laboratories were mapped out in Latin America. Of this total, 22 laboratories were concentrated in universities and academic research institutions (Sperling et al., 2015). At the time, in Brazil, there were 22 laboratories, of which 14 were linked to the MIT Fab and Rhino Fab networks.

In 2017, Brazil had 58 spaces that were called makerspaces, fab labs or digital manufacturing laboratories, which were distributed in 24 cities (Costa \& Pelegrini, 2017). Among those, many were linked to the Faculties of Architecture and Urbanism, Design and Engineering, since they reach the goal of bringing students closer to reality through doing and experimenting. Of the total number of fab labs surveyed by the authors, 29 were associated with universities. That is, more than half of the fab labs in Brazil's universities found the necessary balance, both in terms of infrastructure and human and financial resources, for their existence and maintenance.

Today, there are 49 Brazilian fab labs linked to the Fab Foundation (https://www.fablabs.io/labs?country=br) and $23 \mathrm{fab}$ labs listed in the Fab Lab Brazil Network 
(https://www.fablabs.io/organizations/rede-fab-lab-brazil), also affiliated with Fab Foundation.

It should be noted that there are still many laboratories equipped with digital machinery that are not present in these statistics of Fab Foudation or the Fab Lab Brazil Network. This is the case of the Laboratory LEAUD, linked to the Faculty of Architecture and Urbanism and the Graduate Program of Built Environment, from the Federal University of Juiz de Fora, to which the authors of this paper are affiliated, which features 3D printer, milling machine and cutting plotter.

Because they have a small structure, almost always the result of small funds of research projects, these laboratories eventually establish collaboration partnerships within the universities themselves or through external partners. Thus, these laboratories use the principles of data sharing among themselves, fostering the open source universe and democratizing techniques and knowledge in a fast and collaborative way.

Thus, as in the most diverse fields of knowledge, also in Architecture, Urbanism and Design, the maker culture finds fertile ground to establish itself within a less hierarchical and more collaborative knowledge and production dynamics, where then role of a single author is questioned, since, with each passing day, a collective intelligence, already advocated by Lévy (2000), founded on a society connected by the digital networks, is constituted with greater force

\section{METHODOLOGY}

This article is the result of a qualitative research, based both on a theoretical and empirical approach, on the universe of the maker culture in contemporary society. The theoretical basis of the research is grounded, more specifically, on the literature review about the maker culture and its impacts in the fields of Architecture, Urbanism and Design, as well as on the open source model as one of the foundations of the digital era.

The discussion of the maker culture has been approached by several authors, such as Hatch (2016) and Anderson (2012). And it is this culture that has been unveiled in the new millennium, a period already identified as the fourth industrial revolution, industry 4.0, era of the advanced or intelligent manufacturing, among others. These terms appear recurrently in the book 101 concepts of architecture and urbanism in the digital age, organized by Braida et al. (2016).

In the scope of Architecture, Urbanism and Design, both internationally and nationally, several initiatives that seek to reconcile the design practices linked to digital thinking, the development of prototypes and products in fab labs are assisted. Sperling et al. (2015), Costa and Pelegrini (2017) and Rosa et al. (2018) contribute to a mapping of makers spaces in Latin America, especially in Brazil.

The bibliographical survey on the theme of space makers and fab labs linked to the schools of Architecture, Urbanism and Design, often presents a transformation of the old carpentry and scale model in spaces of digital manufacture, whose premises of the maker culture are present, almost always coordinated by enthusiastic researchers and scholarship holders.

It is within this universe that fits the development, production and distribution of the building blocks game Archbricks. The game is the result of a research on the blocks as didactic material for the formal design of the Architecture design, whose premises were linked to the maker movement in general, digital manufacturing, collaborative process, open source content and free distribution by Internet.

Therefore, methodologically, in addition to literature review (theoretical research), this article is also the result of a critical review of the design, development, production and distribution of a proposed product within the premises and precepts of maker culture (empirical research).

\section{RESULTS}

As one of the main results of the theoretical research, there is a congruence between the maker culture, the open source model and the contemporary democratization of access to knowledge, through the use of technological devices (Zanetti, 2014). Therefore, the literature review points to the potential of the design, production and distribution processes of products and information based on the premises of open source and do-it-yourself.

It is in this sense that is inserted the experience of availability on the internet of the game directed for the architecture project, designed to be downloaded freely, modified and produced with digital manufacturing technology by any user, located anywhere, provided that it has access, from somehow, to a computer connected to the internet, editing software (three-dimensional modeling) and a 3D printer.

\section{THE GAME ARCHIBRICKS: CONCEPTIONS ASSUMPTIONS}

The games are present in the life of the mankind from the initial stages, playing different social roles. Whether they are digital or physical, the building blocks have a strong potential in the teaching of Architecture design, as they awaken, in a ludic way and through a concrete material, creativity, enabling volumetric compositions, whose dimensions coincide with the three-dimensionality of the architectural and urbanistic space.

Among the various sets of assembling blocks (with or without fittings) available on the market, the Fröbel (Fröebel gifts) and LEGO games can be highlighted. According to Marquéz (2012), the Fröebel blocks were even used by Frank Lloyd before the invention of LEGO in 1958.

However, even today, many of the games available for purchase are expensive and / or have a restricted number of pieces, factor that, almost always, is presented as limitations for the use of games as didactic material by teachers in the schools of Architecture and Urbanism.

Based on this assumption, we tried to produce a game that was financially accessible and cost-effective. In this sense, the use of digital manufacturing technologies proved to be feasible, since customizes parts could be manufactured at a relatively low cost.

3 
The proposal of the game was based on an empirical analysis of 10 games acquired and tested, identifying its limits and possibilities for use in the volumetric phase of architectural design. At the end, a briefing was held that included the development of a game of modular parts, simple volumetry, endowed with fittings and manufactured with digital technology.

For main reference of formal language, the games of Fröbel were used, due to their simple shape parts and their ability to congruence with reality, and LEGO blocks, according to the fittings.

\section{THE DEVELOPMENT OF THE GAME PRODUCTION}

In order to achieve the final version of the game, tests were made with pieces made of wood, with the aid of a laser cutting machine. However, the option to use a 3D printer was more feasible due to the search for the creation of pieces with fittings

It should be noted that the option to manufacture with a 3D printer enabled the production of light, resistant parts with high quality of finishing, low post-processing needs and of easy transportation. The material indicated for its production is the biodegradable PLA (polylactic lactic acid), filament derived from maize starch, resulting in a sustainable game (Figure 1).

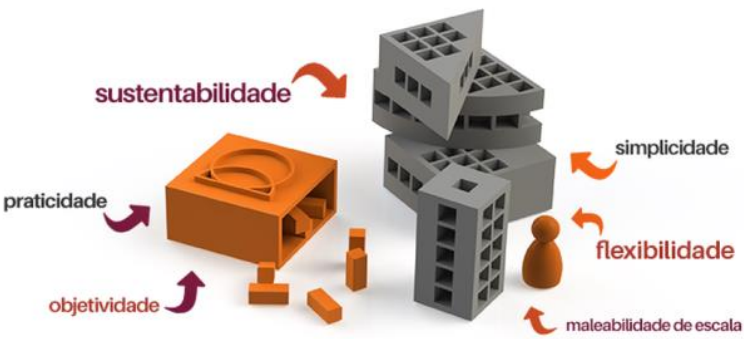

Instrumentos que ajudam a concepção de volumes arquitetônicos

Figure 1: Characteristics of the game. Source: authors.

Thus, a game was made up of four different basic pieces, derived from the transformation of a square-shaped prism $(3 \times 3 \mathrm{~cm})$ with a height of $1.5 \mathrm{~cm}$. There are, therefore, prismatic pieces of triangular base (rectangular triangle isosceles, base and height of $3 \mathrm{~cm})$, rectangular $(3 \times 1.5$ $\mathrm{cm}$ ) and a quarter of a circle (of radius equal to $3 \mathrm{~cm}$ ); all prisms with a height of $1.5 \mathrm{~cm}$. Therefore, the pieces start from a module that can be easily used in the 1: 100 scale.

In addition to the main composition pieces of the game, its basic kit also has connectors, a human scale piece (1.7 $\mathrm{cm}$ high) and a box to store the last two elements (Figure 2).

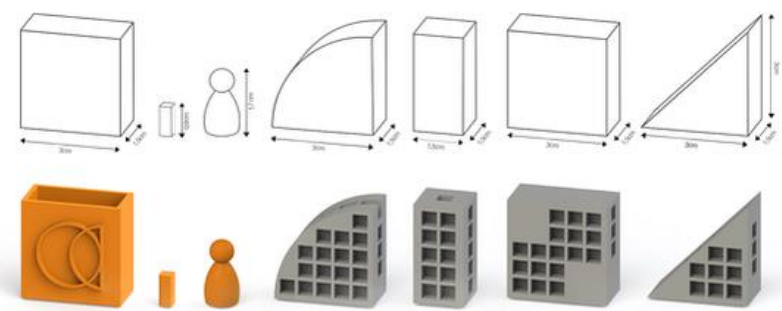

Figure 2: Set of pieces that make up the set of blocks. Source: authors.
However, imbued with a maker spirit, the desire of the researchers / developers of the game was that the pieces could be manufactured by the players themselves. Therefore, within an open source policy, four initial pieces were designed, which can be transformed by the users, who can construct other complementary pieces, altering the form and scale initially proposed. Although there are a number of pieces suggested, the total number is up to each player, respecting their demand and their availability for printing.

\section{THE DISTRIBUTION OF THE GAME}

The game Archbricks is distributed through its own site https://archbricks.weebly.com/, in addition to being on other platforms. Information on game design, a brief history, examples of projects developed with the game, main characteristics, technical data, data of the authors, the funding agency and the Higher Education Institution to which the game is linked, are available in the website, download link for parts and contact forms (Figure 3).

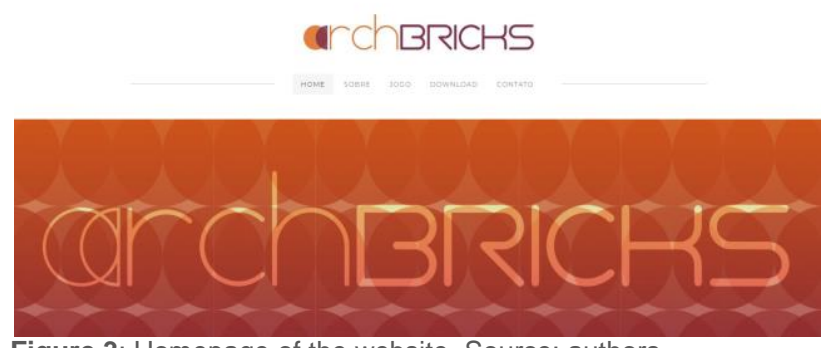

Figure 3: Homepage of the website. Source: authors.

Downloadable files are available for download, which can be downloaded quickly, free of charge, after completing a short form. Such form proves to be important not for control, but so that it may be mapped the scope and use of the game. The form includes only four fields that are filled with data that are archived for consultation of the project authors, in order to generate inputs for future versions. It is the full name, contact (email), age and whether the user is linked to any educational institution.

Once the data above is completed, the user is directed to a site where he can download a file with all the compacted parts. The estimated maximum download time is approximately three seconds.

Some suggestions on printer configuration, such as nozzle gauge extruder, filament type, and temperature are also available on the website. Thus, the user already has an initial parameter to adjust their own 3D printer.

\section{APLICATIONS OF THE GAME}

Since the conclusion of current Archbricks version, some workshops have been organized to understand how users can explore that, so we can suggest some improvements for future versions of the game. The strategy of the workshops has proved to be very valid in the Archbricks development process. The results achieved in a workshop carried out with the first version of the game can be checked in Braida et al. (2017).

The most recent application of the game was a three-hour workshop, which the aim was to verify the viability of Archbricks' number of pieces for different architectural projects of compact houses. Students of the first period of Faculty of Architecture and Urbanism of the Federal 
University of Juiz de Fora (FAU / UFJF) joined the empirical experience of the game. It is convenient to highlight that none of them had a great experience in architecture design.

The task was organized in two moments: (1) a brief presentation about the research group and the game, an explanation of workshop's theme (Memorials), proposition of activities, team's formation and design of a memorial; (2) after that, teams were supposed to present their projetcs and then there was a debate on the results achieved, as well as on the challenges and advantages found by using Archbricks.

In the end, it was observed that students were able to dialogue with Archbricks' formal grammar and, although they were first years' students and the workshop were a quick exercise, it showed up interesting results, which indicates the viability of the game for design process. It is important to underline that each group worked only with the parts provided in the basic kit. In addition, it was noted that students felt inspired by the results and intend to use that inspiration in future graduation activities (Figure 4).

Besides many workshops and activities, one of the applications of the game was presented at an exhibition entitled "Designing with Games to Ride", which was shown in April 2018 in the Rectory Hall of the Federal University of Juiz de Fora (ArchDaily Brasil, 2018). The main goal of the exhibition was to launch the Archbricks game, presenting to the whole community the results of the research, the trajectory of its conception, as well as some of its possibilities (Figure 5).

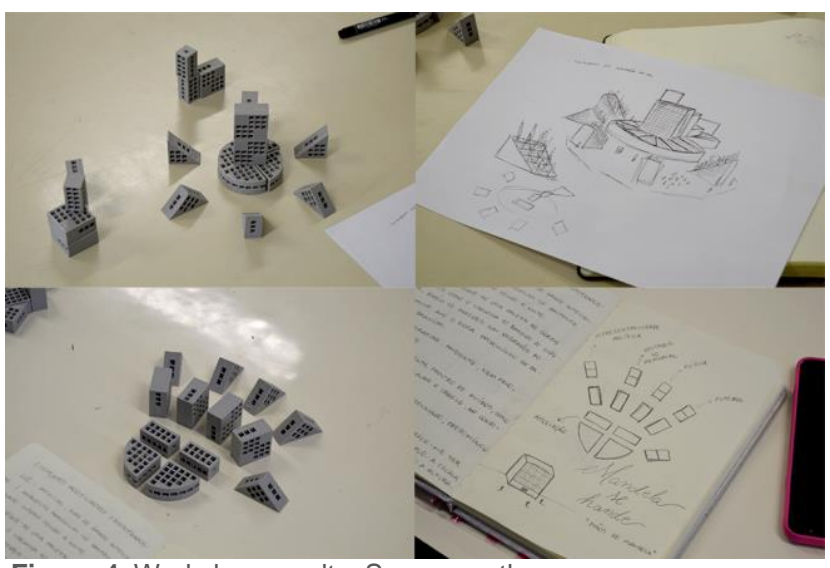

Figure 4: Workshop results. Source: authors.

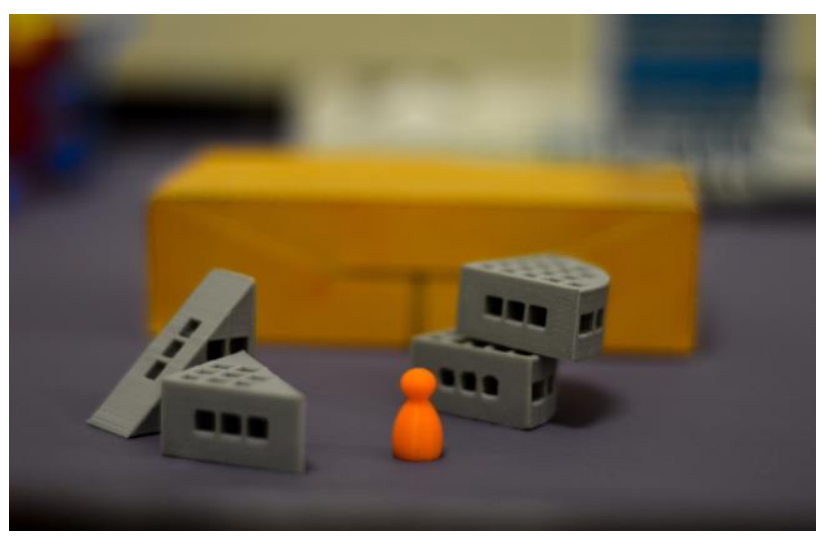

Figure 5: The game on the exhibition. Source: authors.

\section{DISCUSSION}

As can be seen, the maker culture and the open source model have generated significant changes within contemporary society. Such changes eventually spread to all areas of human knowledge (Halverson \& Sheridan, 2014), including for the fields of Architecture, Urbanism and Design, demanding from researchers and professionals new reflections and positions on this subject.

Thus, this article presents a research project that resulted in the design, production and distribution of a game designed according to the premises of the maker culture, designed to provide collaborative acts and the nonhierarchical diffusion of knowledge.

As it is known, there is still a great gap in the supply of didactic material for the teaching of Architecture project, especially of materials that concretely explore the formal and volumetric language of the architectural space. For Brazilian schools, the acquisition of the few available materials, almost always imported, becomes even more difficult and costly.

Therefore, the game Archbricks proposes, rather modestly, to contribute to the reduction of this gap. It should be noted that, given the availability of a 3D printer, the game presents low cost (especially if compared to the costs of acquiring other sets of assembling blocks) and easy reproduction. The flexibility of number of parts must also be evidenced, since the user manufactures the quantity by him demanded. Another fact to be mentioned is the malleability of the scale, since the user is free to increase or decrease the size of the pieces according to their need

Thus, it can be seen that one of the main advantages of the game Archbricks, compared to the other assembling blocks studied, is that it can be purchased free of charge, modified and manufactured by the user himself, with a computer equipped with the necessary software for modeling and a 3D printer.

Currently the game Archbricks is in a phase of dissemination and distribution, in such a way that, from the wide access and use of the game, new developments will be evidenced. However, some reflections resulting from the critical analyzes carried out throughout the entire game development process deserve to be mentioned.

The first of these is the paradigm shift of researchers who increasingly need to learn how to construct their research projects within a culture of collaboration and sharing, even if some part of exclusive domain and control over products and knowledge resulting from their research. Thus, although the game Archbricks was designed by a multidisciplinary team, it is expected that the collaboration of users spread around the world could bring significant contributions to the improvement of the current version.

Secondly, it is believed that the production of noncentralized knowledge and its free distribution have much to contribute to the advancement of knowledge in several fields of human knowledge, among which include Architecture, Urbanism and Design. It is in this sense that the institutions that shelter fab labs can, by opening their doors to collaborative actions, constitute spaces for 
creativity and innovation, so demanding in the contemporary world.

It is also worth remembering that with digital networks, geographic barriers are minimized, so that individuals who are physically distant, as long as they are connected (and endowed with digital resources and technologies), can be empowered. It is in this sense that the game Archbricks seeks to make its contribution. When made available on the Internet, it is intended to overcome s

\section{FINAL CONSIDERATION}

The main issue addressed in this paper concerns the impacts and unfolding of the maker culture for contemporary society, especially in the ambit of Architecture, Urbanism and Design. As we have seen in the literature review, and also by means of empirical examples, we are in a moment of a great change of cultural paradigms and of production (of manufactures and knowledge), which has been understood as a new industrial revolution.

The current moment, then, demands a new posture from educational institutions, teachers, researchers and students. In fact, the whole society is summoned to review their roles, mainly signified by digital technologies.

It is in this sense that we sought to develop the research that resulted in the production of the set of assembling blocks, initiative based largely on the digital culture that aims to encourage flexible, collaborative, creative and innovation processes, premises prevailing in the maker movement.

Finally, it is hoped that this article may contribute to the debate about the incorporation of the maker culture in the scenario of Architecture, Urbanism and Design and of some themes inherent to this movement, once the development of the research presented here activates some themes that are peculiar, such as: digital fabrication (digital printing), the empowerment of contemporary homo faber (do it yourself) and the open source universe (open code), as well as free access to information, content and knowledge

\section{ACKNOWLEDGMENTS}

We thank the Foundation for Research Support of the State of Minas Gerais (FAPEMIG), for the financial resources assigned to the execution of the research project (TEC APQ 01041/14 and TEC PPM 00766/15), of which resulted this article. We are also grateful to CAPES, $\mathrm{CNPq}$ and the Federal University of Juiz de Fora (UFJF) for the scholarships for research academics, and the Graduate Program of Built Environment, for making the presentation of this article possible in the XXII SIGraDi. Finally, the authors thank everyone who contributed, directly or indirectly, to the development of the game presented in this article.

\section{REFERENCES}

Ames, M. G. et al. (2014). Making cultures. In Proceedings of the extended abstracts of the 32nd annual ACM conference on Human factors in computing systems - CHI EA'14. New York, New York, USA: ACM Press, 1087-1092. Retrieved from http://dl.acm.org/citation.cfm?doid=2559206.2579405
Anderson, C. (2012). Markers: a nova revolução industrial. São Paulo: Elsevier.

ArchDaily Brasil (2018). Exposição "Projetando com jogos de montar". Retirado de https://www.archdaily.com.br/br/892740/exposicao-projetandocom-jogos-de-montar

Braida, F. et al. (Orgs.). (2016). 101 conceitos de arquitetura e urbanismo na era digital. São Paulo: ProBooks.

Braida, F. et al. (2017). Projetando com blocos de montar: residências mínimas no contexto da cidade contemporânea. In: Anais do XXI Congresso Internacional da SIGraDi. São Paulo: Blucher, p. 303-310. DOI 10.5151/sigradi2017-048.

Costa C. \& Pelegrini A. (2017). O Design dos makerspaces e dos fablabs no Brasil: um mapeamento preliminar. Retirado de https://dialnet.unirioja.es/servlet/articulo?codigo=6137560

Dunn, N. (2012). Proyecto y construcción digital en arquitectura. Barcelona: Blume.

Gershenfeld N. (2012). How to make almost anything: the digital fabrication revolution. Foreing Affairs, 91 (6), 43-57. Retrieved from http://cba.mit.edu/docs/papers/12.09.FA.pdf

Halverson, E. \& Sheridan, K. (2014). The maker movement in education. Harvard Educational Review, 84 (4), 495-504. Retrieved from http://dx.doi.org/10.17763/haer.84.4.34j1g68140382063

Hatch, M. (2016). Maker manifesto: rules for the new world of crafters, hackers and tinkners. New York: Mc Graw Hill Education.

Kera, D. (2017). Maker culture liminality and open source (science) hardware: instead of making anything great again, keep experimenting! Liinc em revista, 13, 1. Retrieved from http://revista.ibict.br/liinc/article/view/3875

LEAUD (2018). Archbricks. Site. Retirado de https://Archbricks.weebly.com/

Lévy, P. (2000). A inteligência coletiva: por uma antropologia do ciberespaço. São paulo: Edições Loyola.

Márquez, L. (2012). LEGO completa 80 anos e permanece arquitetonicamente impressionante. ArchDaily Brasil. Retirado de http://www.archdaily.com.br/73619/legocompleta-80-anos-e-permanece-arquitetonicamenteimpressionante

Mellis, D. A. \& Buechley, L. (2011). Scaffolding creativity with open-source hardware. In Proceedings of the 8th ACM conference on Creativity and cognition - C\&C '11. New York, New York, USA: ACM Press, 373-374. Retrieved from http://dl.acm.org/citation.cfm?doid=2069618.2069702

Okada, A. (2017). Novos paradigmas na educação online com a aprendizagem aberta. In Proceedings of Challenges. Braga, Portugal. Retrieved from http://oro.open.ac.uk/28633/1/CHALLENGES2007.pdf

Pacini G., Passaro A. \& Henriques G., (2017). Fab!t, pavilhão itinerante de ensino: proposta para inserção da cultura maker no ensino tradicional. In Anais do SIGraDi 2017. São Paulo: Blucher, 170-177. Retirado de http://pdf.blucher.com.br.s3sa-east-

1.amazonaws.com/designproceedings/sigradi2017/027.pdf

Rosa, P. C., Bernardes, M. M. S. \& Bruscato, U. M. (2018). Análise do perfil dos gestores de espaços makers profissionais na cidade de Porto Alegre. Gestão e Tecnologia de Projetos, São Carlos, 13, 1, 115-126. Retrieved from https://www.revistas.usp.br/gestaodeprojetos/article/view/134 484 
Schön S., Ebner M. \& Kumas S. (2014). The maker movement. implications of new digital gadgets, fabrication tools and spaces for creative learning and teaching. Retrieved from https://www.openeducationeuropa.eu/sites/default/files/asset/ Learning\%20in\%20cyber-physical\%20worlds_Indepth_39_2_0.pdf

Schwab, K. (2016). A quarta revolução industrial. São Paulo: Edipro.
Sperling, D. M., Herrera, P. C., Celani, G. \& Scheeren, R. (2015). Fabricação digital na América do Sul: um mapeamento de linhas de ação a partir da arquitetura e urbanismo. In Anais do SIGraDi 2015. São Paulo: Blucher, 119-125. Retirado de http://pdf.blucher.com.br.s3-sa-east-

1.amazonaws.com/designproceedings/sigradi2015/30212.pdf

Weiss, A. (2008). Open source hardware. netWorker, 12 (3), p.26.

Zanetti, H. (2014). A cultura maker na educação. Retirado de http://blog.fazedores.com/cultura-maker-na-educacao/ 